\title{
RESEÑA DEL LIBRO \\ "Direitos do Consumidor no Mercosul e na União Européia" DE EdUARdo ANTONIO KLAUSNER ${ }^{1}$
}

\section{Thomas Richter ${ }^{2}$ \\ María Laura Delaloye ${ }^{3}$}

Este libro, consecuencia de la disertación de mestrado defendida el 11.08 .2004 en la Universidad del Estado de Rio de Janeiro, se encuadra dentro del área del Derecho Procesal Civil Internacional sobre la óptica del Derecho del Consumidor.

La obra, se encuentra dividida en cinco capítulos y tiene por objeto examinar lo que viene siendo realizado para superat las dificultades del ejercicio de los derechos de los consumidores en los conflictos transfronterizos en la Comunidad Europea y en el MERCOSUR; y sugerir soluciones para la superación de las barreras al acceso del consumidor a la justicia aún existentes en éstos ámbitos.

El primer capítulo, nos coloca frente a la situación del consumidor en el contexto internacional, mostrando los nuevos desafios y especificidades de esta relación que lo toman todavía más vulnetable; así como cuales han sido las políticas llevadas a cabo por los dos bloques regionales. Recomendando el autor la necesidad de un concepto unívoco de consumidor dentro de cada bloque y trayendo a la controversia actual ${ }^{4}$ sobre la calificación de las personas jurídicas como consumidores, la posición del Tribunal de Justicia de la Comunidad Europea, quien "ainda não se manifestou sobre a matéria, mas a tendência é de se interpretar que as pessoas juridicas possam ser consideradas consumidores" (p. 79 es.).

\footnotetext{
Klausner, Eduardo Antonio. "Direstos do Consumidor no Mercosul e na Uniâo Européia". Curitiba: Junú, 2006.

Prof. Dr. Thomas Richter, Professor Invitado por la Fuculdad de Derecho, Universidade Federal de Rio Grande do Sul.

María Lazara Delaloye, abogada por la Universidad Nacional del Litoral, mestranda em Direto por la Universidade Federal de Rio Grande do Sul.

4 Vea: los debates preparatorios de la CIDIP VIl en htw://wwwoas.org/dil /esp/derecho_internacional_privado_foro_proteccion_al_consumidorasp

s Vea a este respecto Tibural de fusticia de la Comunidad Europea 22.11.2001, calsos 541 e 542/99-Idealservice, coleta e Fellous p. 136 e s. com más referencias; tandiét 'Tribunal de Justicia 20.1 .2005 .
} 
Pasando el segundo capítulo a tratar un tema que nos parece el medular de esta obra, cual es el acceso a la justicia en conflictos internacionales e intracomunitarios de consumo, para lo cual se estudia la Convención de Bruselas y el Reglamento Europeo 44/20017 y se analiza criticamente el leading case "Panasonic" del Supremo Tribunal de Justicia de Brasil". Aquí también cabe llamar la atención del tratamiento de un tema de tanta actualidad como son las acciones colectivas en lo referente a la tutela de intereses difusos propios a los casos de consumo.

Temas tan comunes a la contratación internacional como la cláusula de elección de foro y el arbitraje, son abordados en el tercer capítulo, una vez más, destacándose sus particularidades en función de la materia. Considera el autor a los métodos altemativos de resolución de conflictos adecuados para tratar el problema que lo ocupa, según lo demuestra la experiencia de la Comunidad Europea (p. 250).

En cuanto a las cartas rogatórias y el reconocimiento y ejecución de sentencias, temas tratados en el cuarto capítulo, se llama a una evolución hacia sistemas más simples de realización de actos jurisdiccionales en el extranjero.

Trayendo el capítulo quinto las conclusiones sobre los temas analizados y un anexo con la sugerencia de nueva redacción del Protocolo de Santa Maria.

Luego de este análisis, nos gustaría resaltar la pertinencia de la obra dada la importancia del tema del consumo internacional y la escasez de trabajos que tratan sobre esta materia.

Así también, creemos importante destacar cl coraje del autor quien, además de realizar un estudio profundo y rico sobre el tratamiento del tema en ambos bloques regionales, trae la propuesta de revitalización del Protocolo de Santa María en el ámbito del MERCOSUR, no deteniéndose aquí, sino incorporando en anexo un modelo de cómo el mismo debería ser re-redactado.

Por lo antes expuesto, no podemos sino felicitar al autor y recomendar esta obra, cuya profundidad y clara redacción hacen de la misma una lectura agradable e instructiva.

\footnotetext{
"Convención de Bnelas de 1968 relativa a competencia judicià y a la ejecucióa de decisiones en materia civil y comercial, Diaxo Oficial CE $1998 \mathrm{n}^{\circ} \mathrm{L} 27, \mathrm{p} .3$.

${ }^{7}$ Reglamento (CE) N.44/2001 del Consejo del 22 de Dicienbre de 2000 relativo a la competencia judicial, al reconocimiento e ejecución de decisiones en miteria civil y comercial, Diatio Oficial CE: 2001 no L 12 de 16.1.2000, p.1.

${ }^{8}$ Superior Thbunal de Justica 20.11.2000, Recurso Especial 63.281/SP, LexSY] $139,59$.
} 